\title{
Kidney stones and hypertension: population based study of an independent clinical association
}

\author{
Francesco P Cappuccio, Pasquale Strazzullo, Mario Mancini
}

Abstract

Objective-To test the hypothesis that kidney stone disease is more frequent among hypertensive men when the effect of possible confounders is allowed for.

Design-Cross sectional study of a sample of the male working population conducted as part of the 10 year follow up of a nationwide survey of the prevalence of cardiovascular risk factors.

Setting-The Olivetti factory in Pozzuoli, a suburban area of Naples.

Population -688 Male workers $(87.9 \%$ of the male workforce) aged 21-68.

Interventions-Anthropometric and blood pressure measurements, blood tests, and administration of a detailed questionnaire aimed at detecting a history of urolithiasis.

Main outcome measures-Prevalence of a history of urolithiasis among normotensive and untreated and treated hypertensive men adjusted for the possible confounding effects of age, body mass index, renal function, and serum urate and total calcium concentrations.

Results - Of the 688 participants 509 were normotensive. Of the remainder, 118 had untreated and 61 treated hypertension. The overall prevalence of a history of urolithiasis was $16 \cdot 3 \%(112 / 688)$. The relative risk of hypertensive subjects having a history of kidney stones was twice that of the normotensive group (odds ratio $2 \cdot 11 ; 95 \%$ confidence interval $1 \cdot 17$ to 3.81 ), the risk being higher when only treated hypertensives were considered (odds ratio $3 \cdot 16$; $95 \%$ confidence interval 1.75 to $5 \cdot 71$ ). The prevalence of a history of urolithiasis was $13.4 \%(68 / 509)$ in the normotensive subjects, $20.3 \%(24 / 118)$ in the untreated hypertensives, and $32.8 \%(20 / 61)$ in the treated hypertensives $(p<0.001)$. The age adjusted relative risk in treated hypertensive men was higher than that in the normotensive group (MantelHaenszel pooled estimate of odds ratio $2.63 ; 95 \%$ confidence interval $2 \cdot 23$ to $3 \cdot 10$ ).

Conclusion-An independent clinical association exists between the occurrence of urolithiasis and hypertension. The increased urinary calcium excretion commonly detected in hypertension may be the pathogenetic link.

Institute of Internal Medicine and Metabolic Diseases, II Medical School,

University of Naples, Via S Pansini 5, 8013 Naples, Italy

Francesco P Cappuccio, MD, senior registrar

Pasquale Strazzullo, MD assistant professor

Mario Mancini, MD, professor of medicine

Correspondence to: Dr Pasquale Strazzullo. patients have an increased 24 hour urinary calcium output due to defective tubular reabsorption of calcium."
Hence, given that hypercalciuria is by and large the most common causal factor in the genesis of urolithiasis, ${ }^{1+15}$ we hypothesised that these patients might be liable to kidney stone disease. On this ground we decided to test the hypothesis that kidney stone disease would indeed be more frequent among hypertensive subjects in a population based survey of male workers after allowing for the effect of several possible confounders.

\section{Population and methods}

The study was carried out at the Olivetti factory in Pozzuoli, a suburban area of Naples. The factory employs mainly men. The study was part of the 10 year follow up of a nationwide survey of the prevalence of cardiovascular risk factors sponsored by the National Research Council and started in 1976-7. ${ }^{16-20}$ Between April 1987 and May 1988 a sample of 783 men aged 21-68 were seen who represented the male workforce employed at the time. Six hundred and eighty eight of them $(87.9 \%)$ had all the investigations done (see below), including blood tests, and were thus included in the final analysis. The examinations were carried out in the morning, with the participants fasted, in a quiet, comfortable room at the factory. Participants were allowed to go about their normal activities but were discouraged from vigorous exercise and were asked to refrain from smoking and not to drink alcohol, coffee, or other beverages containing caffeine during the morning of the study. The study included a physical examination, resting electrocardiography, a blood test, and the administration of a detailed questionnaire.

Age was recorded at last birthday. Body weight and height were taken on a standard beam balance scale with an attached rule, participants wearing indoor clothing and no shoes. The body mass index was calculated as the weight in $\mathrm{kg}$ divided by the square of the height in $\mathrm{m}\left(\mathrm{kg} / \mathrm{m}^{2}\right)$. Blood pressure was measured between 0800 and 1100 after the subject had been sitting upright for at least 10 minutes. Systolic and diastolic (phase V) blood pressures were taken three times two minutes apart with a random zero sphygmomanometer (Gelman Hawksley Ltd) by trained observers who had attended blood pressure training sessions for standardisation of the reading procedure. The first reading was discarded and the average of the second two readings recorded. Participants were classified as normotensive $(n=509)$ if they had a systolic blood pressure $<160 \mathrm{~mm} \mathrm{Hg}$ and a diastolic pressure $<95 \mathrm{~mm} \mathrm{Hg}$, and as hypertensive $(n=179)$ if they had a systolic pressure $\geqslant 160 \mathrm{~mm} \mathrm{Hg}$ or a diastolic pressure $\geqslant 95 \mathrm{~mm} \mathrm{Hg}$ (untreated group, $\mathrm{n}=$ 118 ) or if they were receiving regular pharmacological treatment for high blood pressure (treated group, $\mathrm{n}=61$ ).

Venous blood was taken (after the blood pressure measurements) with the subject seated and without stasis between 0800 and 1100 for determination of serum electrolyte, creatinine, total calcium, and urate concentrations by standard methods.

A questionnaire administered by one trained observer unaware of the man's blood pressure included 
information on socioeconomic state, lifestyle, dietary habits, and family history of cardiovascular and renal diseases. A detailed and fixed sequence of questions aimed at detecting a history of upper urinary tract stones. As we could not distinguish between kidney and ureteric stones we use the term "kidney stones" as synonymous with upper urinary tract stones. Men were classified as having a history of kidney stones if they met one or more of the following criteria: $(a)$ characteristic clinical findings judged by a physician at the time of symptoms, with available medical records (clinical criteria were one or more episodes of the sudden onset of excruciating flank pain radiating downwards towards the groin (with or without painful haematuria) and the detection of calcium oxalate or urate crystals on urine analysis); $(b)$ spontaneous passage of a stone; $(c) x$ ray or ultrasonic evidence of stones in the upper urinary tract; $(d)$ operative removal of stones from kidney or ureter.

Statistical analysis-Analysis of variance with Duncan's test for multiple comparison was used to test differences between means and analysis of covariance used to obtain adjusted frequencies for possible confounders. The Wilcoxon rank sum test was used to test differences between median values of several variables in groups with and without a history of kidney stones. $\chi^{2}$ Cross tabulation statistics, with Yates's correction when necessary, were used to test differences between frequencies. In addition, the odds ratio and $95 \%$ confidence interval were taken as an approximate estimate of the relative risk of the disease (definite history of kidney stones) associated with exposure to the factor (hypertension)..$^{21}$ The Mantel-Haenszel pooled estimate of the odds ratio and $95 \%$ confidence interval were also used in stratified analyses to control for the effect of age. ${ }^{22}$ Two tailed $p$ values less than 0.05 were taken as significant.

\section{Results}

The prevalence of hypertension in this sample of men was $26 \cdot 0 \%(179 / 688)$, and $8 \cdot 9 \%(61 / 688)$ of the men were receiving pharmacological treatment for high blood pressure at the time of screening. Most of the treated hypertensive participants (37/61) were taking diuretics (thiazides in 35 cases) either alone (17/ $61)$ or in combination with other antihypertensive

TABLE I-Characteristics of study population $(n=688)$. Except where stated otherwise figures are means ( $S D$ in parentheses)

\begin{tabular}{|c|c|c|c|c|}
\hline & \multirow{2}{*}{$\begin{array}{c}\text { Normotensive } \\
\text { subjects }\end{array}$} & \multicolumn{2}{|c|}{ Hypertensive subjects } & \multirow{2}{*}{$\begin{array}{c}\mathrm{p} \text { Value } \\
\text { (analysis of } \\
\text { variance) }\end{array}$} \\
\hline & & Untreated & Treated & \\
\hline No & 509 & 118 & 61 & \\
\hline Age (years) & $45 \cdot 3(7 \cdot 5)$ & $48 \cdot 4(7 \cdot 1)^{\star}$ & $51 \cdot 8(7 \cdot 7) \dagger$ & $<0.001$ \\
\hline Weight $(\mathrm{kg})$ & $72 \cdot 5(9 \cdot 3)$ & $79 \cdot 5(9 \cdot 8)^{\star}$ & $77 \cdot 8(9 \cdot 2)^{\star}$ & $<0.001$ \\
\hline Height $(\mathrm{cm})$ & $167 \cdot 9(6 \cdot 0)$ & $169 \cdot 0(6 \cdot 0)$ & $167 \cdot 6(6 \cdot 6)$ & NS \\
\hline Body mass index $\left(\mathrm{kg} / \mathrm{m}^{*}\right)$ & $25 \cdot 7(2 \cdot 9)$ & $27 \cdot 8(2 \cdot 7)^{\star}$ & $27 \cdot 7(3 \cdot 0)^{\star}$ & $<0.001$ \\
\hline \multicolumn{5}{|l|}{ Blood pressure $(\mathrm{mm} \mathrm{Hg})$ : } \\
\hline Systolic & $120 \cdot 6(11 \cdot 6)$ & $143.9(14.4)^{\star}$ & $149 \cdot 1(24 \cdot 0)+$ & $<0.001$ \\
\hline Diastolic & $82.6(6.9)$ & $100 \cdot 4(6 \cdot 0)^{\star}$ & $98.0(11 \cdot 7) t$ & $<0.001$ \\
\hline Serum sodium $(\mathrm{mmol} / \mathrm{l})$ & $140 \cdot 2(2 \cdot 2)$ & $139 \cdot 7(2 \cdot 2)$ & $140 \cdot 3(2 \cdot 0)$ & NS \\
\hline Serum potassium $(\mathrm{mmol} / \mathrm{l})$ & $4.36(0 \cdot 38)$ & $4 \cdot 31(0 \cdot 38)$ & $4 \cdot 20(0 \cdot 48)^{\star}$ & $<0.009$ \\
\hline Serum total calcium (mmol/l) & $2 \cdot 21(0 \cdot 11)$ & $2 \cdot 23(0 \cdot 10)$ & $2 \cdot 23(0 \cdot 13)$ & NS \\
\hline Serum urate $(\mu \mathrm{mol} / \mathrm{l})$ & $305(58)$ & $330(59)^{\star}$ & $364(78) \dagger$ & $<0.001$ \\
\hline Serum creatinine $(\mu \mathrm{mol} / \mathrm{l})$ & $96 \cdot 2(8 \cdot 8)$ & $99.5(11.9)^{\star}$ & $101.8(13.1)^{\star}$ & $<0.001$ \\
\hline No (\%) with history of kidney stones & $68(13 \cdot 4)$ & $24(20 \cdot 3) \neq$ & $20(32 \cdot 8) 5$ & $<0.001$ \\
\hline
\end{tabular}

${ }^{\star} \mathrm{p}<0.05$ Compared with normotensive subjects (Duncan's test for multiple comparison).

$t \mathrm{p}<0.05$ Compared with both normotensive and untreated hypertensive subjects (Duncan's test for multiple comparison).

$\ddagger \mathrm{p}<0.05$ Compared with normotensive subjects $\left(\chi^{2}\right.$ test $)$.

$\S \mathrm{p}<0.05$ Compared with both normotensive and untreated hypertensive subjects $\left(\chi^{\prime}\right)$.
TABLE III - Analysis of selected variables in relation to history of kidney stones. Figures are medians (interquartile range in parentheses) ${ }^{\circ}$

\begin{tabular}{lcc}
\hline & \multicolumn{2}{c}{ History of kidney stones } \\
\cline { 2 - 3 } & $\begin{array}{c}\text { Absent } \\
(\mathbf{n}=576)\end{array}$ & $\begin{array}{c}\text { Present } \\
(\mathbf{n}=112)\end{array}$ \\
\hline Age $($ years $)$ & $45 \cdot 0(42-50)$ & $49 \cdot 0(45-55) \star \star \star$ \\
Body mass index $\left(\mathrm{kg} / \mathrm{m}^{2}\right)$ & $26 \cdot 1(24 \cdot 3-28 \cdot 0)$ & $26 \cdot 4(25 \cdot 0-28 \cdot 2)$ \\
Serum total calcium $(\mathrm{mmol} / \mathrm{l})$ & $2 \cdot 20(2 \cdot 15-2 \cdot 30)$ & $2 \cdot 20(2 \cdot 15-2 \cdot 29)$ \\
Serum urate $(\mu \mathrm{mol} / \mathrm{l})$ & $309(268-351)$ & $303(268-351)$ \\
Serum creatinine $(\mu \mathrm{mol} / \mathrm{l})$ & $96 \cdot 0(90 \cdot 0-102 \cdot 0)$ & $99 \cdot 0(92 \cdot 0-103 \cdot 0)$ \\
\hline$\star \star \star \mathrm{p}<0 \cdot 001(\mathrm{~W}$ ilo &
\end{tabular}

drugs (20/61). Other treatments included $\beta$ blockers $(10 / 61)$, calcium channel blockers $(10 / 61)$, angiotensin converting enzyme inhibitors (2/61), and centrally acting drugs (2/61).

Hypertensive participants were older and heavier than the normotensive group (table I). The serum potassium concentration was lower in men receiving treatment for hypertension, probably owing to the long term use of diuretics. The serum urate concentration was high in men with hypertension and especially so in those having regular treatment. Serum total calcium did not differ among the groups and no participant had hypercalcaemia. Men with hypertension had higher serum creatinine concentrations independently of age and body mass index $(\mathrm{F}=10 \cdot 2 ; \mathrm{p}<0.001$ (analysis of covariance)), but none had values $>160 \mu \mathrm{mol} / \mathrm{l}$.

The overall prevalence of a history of kidney stones in the study population was $16 \cdot 3 \%(112 / 688)$. Of these men, $6 \cdot 7 \%(46 / 688)$ satisfied criterion $(a)$ for a history of stones, $2 \cdot 3 \%(16 / 688)$ criterion $(b), 6 \cdot 7 \%(46 / 688)$ criterion $(c)$, and $0 \cdot 6 \%(4 / 688)$ criterion $(d)$. A history of kidney stones was more frequent among hypertensive men. Prevalences were $32 \cdot 8 \%(20 / 61)$ in the treated hypertensive group, $20.3 \%(24 / 118)$ in the untreated hypertensive group, and $13 \cdot 4 \%(68 / 509)$ in the normotensive group $\left(\chi^{2}=16 \cdot 8 ; p<0.001\right)$ (table I). The relative risk of men with both untreated and treated hypertension having a history of kidney stones was more than twice that of normotensive men drawn from the same population (odds ratio $2 \cdot 11$; $95 \%$ confidence interval $1 \cdot 17$ to $3 \cdot 81$ ). Men in the treated hypertensive group (presumably those with more severe hypertension) had a relative risk of having a history of kidney stones over three times higher than that of the normotensive men (odds ratio $3 \cdot 16$; $95 \%$ confidence interval $1 \cdot 75$ to $5 \cdot 71$ ).

Table II shows that the prevalence of a history of kidney stones increased with age. Participants with a history of kidney stones were significantly older than those without such a history $(\mathrm{p}<0.001)$, but comparisons of other potentially confounding variables (table III) showed no significant differences.

Table IV shows the prevalence of a history of kidney stones in normotensive and untreated and treated hypertensive men adjusted for the confounding effect of age. The adjusted prevalence remained higher among participants with hypertension (treated group $29 \%$, untreated group $18 \%$ ) than among the normotensive men (14\%) $(\mathrm{F}=4.54 ; \mathrm{p}<0.011$ (analysis of covariance); table IV). This pattern was unchanged when the effects of body mass index and serum creatinine, urate, and total calcium concentrations were accounted for $(F=4.58 ; p=0.011$ (analysis of covariance)).

The age adjusted relative risk of men with hypertension having a history of kidney stones remained

TABLE II - Prevalence of history of kidney stones in various age groups. (Entire study population; $n=688$ )

\begin{tabular}{lcccccccc}
\hline Age (years): & $<35$ & $35-39$ & $40-44$ & $45-49$ & $50-54$ & $55-59$ & $>59$ & Total \\
\hline $\begin{array}{c}\text { No }(\%) \text { of subjects with } \\
\text { history of stones: }\end{array}$ & $1 / 40(2 \cdot 5)$ & $2 / 23(8 \cdot 7)$ & $24 / 224(10 \cdot 7)$ & $31 / 198(15 \cdot 7)$ & $22 / 95(23 \cdot 2)$ & $23 / 73(31 \cdot 5)$ & $9 / 35(25 \cdot 7)$ & $112 / 688(16 \cdot 3)$
\end{tabular}


nearly twice that of normotensive men (MantelHaenszel pooled estimate of odds ratio $1.79 ; 95 \%$ confidence interval 1.53 to 2.09 ). In treated hypertensive men the Mantel-Haenszel pooled estimate of odds ratio for the age adjusted relative risk was 2.63 ( $95 \%$ confidence interval $2 \cdot 23$ to $3 \cdot 10$ ).

TABLE IV-Age adjusted prevalence of history of kidney stones in relation to hypertension

\begin{tabular}{lc}
\hline & $\begin{array}{c}\text { Age adjusted } \\
\% \text { with } \\
\text { history of stones }\end{array}$ \\
\hline Normotensive subjects $(\mathrm{n}=509)$ & 14 \\
Untreated hypertensive subjects $(\mathrm{n}=118)$ & 18 \\
Treated hypertensive subjects $(\mathrm{n}=61)$ & 33 \\
\hline $\mathrm{F}=4 \cdot 54 ; \mathrm{p}<0 \cdot 011$ (analysis of covariance)
\end{tabular}

\section{Discussion}

This population based survey provides evidence of a clinical association between kidney stone disease and arterial hypertension and of the independence of this association from such potential confounders as age, body mass index, hyperuricaemia, and hypercalcaemia. Although a history of kidney stones was definitely related to the age of the subjects at the time of interview, the association of such a history with arterial hypertension remained highly significant after controlling for age. This agrees with a preliminary report from a similar study in central Italy.

The study also indicates that hyperuricaemia is not a major factor in the higher prevalence of urolithiasis in hypertension. Though these patients may have a higher serum concentration ${ }^{24} 25$ and an increased filtered load ${ }^{26}$ of uric acid, they also have an enhanced reabsorption of urates in the proximal tubule. ${ }^{20}$

The prevalence of urolithiasis in our population increased stepwise from the normotensive state to the untreated hypertensive state and to the treated hypertensive state. This feature is consistent with the hypothesis that an as yet undetermined pathogenic factor linking high blood pressure and kidney stones was operating in relation to the severity of the hypertension (or was more prevalent in hypertension of severe degree). That the hypertension was more severe in the treated group than in the untreated group was plainly evidenced by the similar mean blood pressures in the two groups (that is, despite treatment).

What, then, might be the pathogenetic factor linking urolithiasis with hypertension? Hypercalciuria represents the most important risk factor for urolithiasis in adults. ${ }^{1+15}$ We first reported increased 24 hour urinary calcium excretion and a higher prevalence of "hypercalciuria" in patients with essential hypertension $^{13}$ after McCarron et al had found increased calcium output in "spot" urine specimens. ${ }^{27}$ We also found a reduced urinary magnesium to calcium ratio in hypertensive patients ${ }^{28}$ and showed that urinary calcium excretion was higher in these patients at any value of serum ionised calcium, suggesting a primary renal calcium leak as the cause of the hypercalciuria, as also confirmed by higher serum parathyroid hormone concentrations. ${ }^{1327}$ The hypothesis that this renal abnormality was the mechanism linking hypertension with urolithiasis is attractive, especially given the exclusion of most other confounding factors. But cause and effect relations are not proved by statistical associations, and, moreover, the possibility that renal damage caused by stones might contribute to hypertension in some cases, though unlikely, cannot definitely be ruled out.

There is need for a prospective investigation to determine the incidence of urolithiasis and identify specific risk factors for this complication in hyper- tensive patients. Identifying predisposed patients and implementing preventive measures might substantially reduce the social costs of the disease.

We thank Dr E Farinaro, Dr A Scottoni, and Ms $\mathrm{R}$ Bartolomei for supporting the work in the field and the workers of the Olivetti factory at Pozzuoli for their cooperation. We also thank Drs G Barba, E Celentano, A De Leo, G Fusco, R Galasso, N Giorgione, D Giumetti, L Iacoviello, $\mathrm{F}$ Jossa, and S Portolano and Miss L Russo for their help as well as $\mathrm{Mr} \mathrm{R}$ Iacone for his laboratory skills. This work was supported in part by grants from the Ministero Pubblica Istruzione (60\% funds 1985 and 1986) of Italy.

1 Wexler BC, McMurtry JP. Kidney and bladder calculi in spontaneously hepertensive rats. Br f Exp P'athol 1981;62:369-74.

2 Tibblin G. High blood pressure in men aged 50. A population study of men born in 1913. Acta Med Scand 1967; suppl 470:1-84.

3 Larsen JF, Phillip J. Studies on the incidence of urolithiasis. Urol Int 1962;13:53-4.

+ Ljunghall S, Hedstrand H. Epidemiology of renal stones in a middle-aged male population. Acta Med Scand 1975;197:439-45

5 Currie WJC, Turner P. The frequency of renal stones within Great Britain in a gouty and non-gouty population. Brf Urol 1979;51:337-41.

6 Johnson CM, Wilson DM, O'Fallon WM, et al. Renal stone epidemiology: a 25-year study in Rochester, Minnesota. Kidney Int 1979;16:624

7 Bengtsson C, Lennartsson J, Lindqvist $O$, et al. Renal stone diseaseexperience from a population study of women in Gothenburg. Sweden. Scand f L'rol Nephrol 1980;14 (supp 53):39-43.

8 Churchill DN, Maloney CM, Bear J, et al. Urolithiasis-a study of drinking water hardness and genetic factors. I Chronic Dis 1980;33:727-31.

9 Tschope W, Ritz E, Haslback $M$, et al. Prevalence and incidence of renal stone disease in a German population. Klin Wochenschr 1981:59:411-2.

10 Hiatt RA, Dales LG, Friedman GD, et al. Frequency of urolithiasis in a prepaid medical care program. Am 7 Epidemiol 1982;115:255-65.

11 Vahlensieck EW, Bach D, Hesse A. Incidence, prevalence and mortality of urolithiasis in the German Federal Republic. Urol Res 1982;10:161-4.

12 Robertson W'G, Peacock M. Baker M. et al. Studies on the prevalence and epidemiology of urinary stone disease in men in Leeds. Br $\mathrm{J}$ Urol $1983 ; 55: 595-8$

13 Strazzullo $P$, Nunziata $V$, Cirillo $M$, et al. Abnormalities of calcium metabolism in essential hypertension. Clin Sci 1983;65:137-41.

14 Van Den Berg CJ. Urolithiasis. In: Knox FG, ed. Textbook of renal pathophvsiologv. New York: Harper and Row, 1978:262-82.

15 Pak CYC. Pathophrsiology of calcium nephrolithiasis. In: Seldin DW, Giebish G, eds. The kidney physiology and pathophysiology. New York: Raven Press, 1985:1365-79

16 Lewis B, Chait A, Sigurdsson G, et al. Serum lipoproteins in four European communities: a quantitative comparison. Eur f Clin Invest 1978;8:165-73.

17 Strazzullo P, Trevisan M, Farinaro E, el al. Characteristics of the association between salt intake and blood pressure in a sample of male working population in southern Italy. Eur Heart 7 1983;4:608-13.

18 Strazzullo P, Cappucicio FP, Trevisan M, et al. Association between blood pressure, dietary salt intake and family history of hypertension in a five year follow-up study. F Hypertens 1983;1 (suppl 2):159-61.

19 Cappuccio FP, MacGregor GA, Strazzullo P, et al. Characteristics of the distribution of plasma atrial natriuretic peptides in a cross-sectional study of middle-aged untreated male workers. F Cardiovasc Pharmacol 1989;13 (suppl 6):51-4.

20 Strazzullo P, Cappuccio FP, Trevisan $M$, et al. Erythrocyte sodium-lithium countertransport and renal lithium clearance in a random sample of untreated middle-aged men. Clin Sci 1989;77:337-42.

21 Morris JA, Gardner MJ. Calculating confidence intervals for relative risks (odds ratios) and standardised ratios and rates. Br.Med f 1988;296:1313-6.

22 Kleinbaum DG, Kupper LL, Morgenstern H. Epidemiologic research. Principles and quantilative methods. New York: Van Nostrand Reinhold, ciples and quan $1982: 320-76$.

23 Cirillo $M$, Laurenzi $M$. Elevated blood pressure and positive history of kidney stones: results from a population-based study. J Hypertens 1988;6(suppl stones: re

24 Dollery C $\mathrm{C}$, Duncan $\mathrm{H}$, Schumer B. Hyperuricaemia related to treatment of hypertension. Br.Med f 1960;iii:832-5.

25 Breckenridge A. Hypertension and hyperuricaemia. Lancet 1966;i: 15-8.

26 Strazzullo P, Cappuccio FP. Trevisan $M$, et al. Red blood cell sodium-lithium countertransport, blood pressure and uric acid metabolism in untreated healthy men. Am J Hypertens 1989;2:634-6

27 McCarron DA, Pingree PA, Rubin RJ, Gaucher SM, Molitch M, Krutzik S. Enhanced parathyroid function in essential hypertension: a homeostatic response to a urinary calcium leak. Hypertension 1980;2:162-8.

28 Cirillo M, Siani A, Nunziata V, Cappuccio FP, Mattioli PL, Strazzullo P. Reduced urinary ratio $\mathrm{Mg}$ :Ca and kidney stone risk in essential hypertension. Minerva Nefrologica 1983;30:213-6.

(Accepted 22 February 1990)

\section{Correction}

Is uterine growth retardation with normal umbilical artery blood flow a benign condition?

An editorial error occurred at the proof stage in the abstract of this paper by Dr Gerard Burke and others (21 April, p 1044). The first part of the second sentence of the results section should read "Among 55 women with abnormal flow there were two midtrimester abortions, three perinatal deaths, and one case of cerebral irritation in physically normal fetuses." 